\title{
Barriers and Motivations to Exercise in Older African American and European American Women
}

\author{
Petra B. Schuler, Jane L.P. Roy, Debra Vinci, Steven F. Philipp, Samantha J. Cohen \\ University of West Florida
}

\begin{abstract}
Older adults, women, and minorities are the least active segments of the US population. The purpose of this study was to identify barriers and motivations to exercise associated with older African American and European American women. Eighty-nine European American and 115 African American women (mean age 72 years) completed a pencil-and-paper questionnaire composed of general demographic information and a list of 10 motivations and six barriers to exercise; participants were asked to check all barriers and motivations that applied to them. Significant ethnic differences were found for one barrier (too expensive) and one motivation (doctor's orders). Significantly more European American women perceived expenses to be a barrier to exercise $\left(\chi^{2}=3.94, \mathrm{p}<0.05\right)$ and significantly more African American women $\left(\chi^{2}=9.79\right.$, $\mathrm{p}<0.01)$ reported they exercised because their doctor told them to compared to the European American women. The African American women in our study were significantly heavier compared to the European American women. The researchers hypothesized that differences in body weight rather than ethnicity might explain the difference in frequency with which the women reported their physician's advice as a motivation to exercise. Physicians might have viewed exercise as a way to treat a problem (i.e., overweight) rather than to prevent it.
\end{abstract}

(C) 2006 Californian Journal of Health Promotion. All rights reserved.

Keywords: Race, exercise, barriers, motivations

\section{Introduction}

Even though the beneficial effects of physical activity are well established, national surveys indicate that at least $60 \%$ of adults in the United States are not regularly active at the recommended level for health. Furthermore, according to recent reports older adults, women, and ethnic minorities constitute the least active segment of the US population (Jones, Ainsworth, \& Croft, 1998; USDHHS, 1996). Studies have begun to explore determinants of physical activity in special populations such as the elderly, women, and minorities. Generally, with respect to older adults, the most frequently cited barriers are health problems, lack of knowledge, and psychological and environmental barriers such as lack of motivation or transportation to facilities (Booth, Bauman, Owen, \& Gore 1997; CohenMansfield, Marx, \& Guralnik, 2003; O'Neill \& Reid, 1991). Other barriers reported in the literature include lack of time, interest, social support (Ebrahim \& Rowland, 1996), and lack of childhood exercise (Schutzer \& Graves, 2004). Important motivations to exercise identified in this population include doctor's advice, improved health and physical condition, and social factors such as spending time with friends (Cohen-Mansfield, Marx, \& Guralnik, 2003; Schutzer \& Graves, 2004).

Few studies have explored ethnic differences in motivations and barriers to exercise in older adults; even fewer studies have explored ethnic differences in barriers and motivations to exercise in older women. Dergance et al. (2003) compared older (mean age 73.8 years) European American and Mexican American's attitudes toward barriers and benefits of physical activity. European Americans were significantly more likely to report lack of interest, self-discipline, enjoyment, and knowledge as a barrier to physical activity compared to Mexican Americans; sex, age, income, marital status, or education did not explain these ethnic differences. Several studies have included older 
women in their sample; however, age-specific analyses were not conducted. For example, King et al. (2000) examined personal and environmental factors associated with physical inactivity in a large ethnically diverse sample of women aged 40 years and older. Even though $35 \%$ of the sample was women aged 60 years and older, age specific analyses were not presented. Mâsse and Anderson (2003) studied ethnic differences among correlates of physical activity in a cross-sectional sample of African American and Hispanic women 40 to 70 years of age (mean age 48 and 50 years, respectively); again, age specific analyses were not reported.

Given the growing number of older adults, the alarmingly low rates of physical activity reported in this segment of the population, and the inherent challenges the aging process poses, such as increased vulnerability to disease and disability, it appears crucial to identify barriers and motivations to exercise which are specific to older adults. Furthermore, it is necessary to recognize barriers and motivations unique to specific subgroups such as older women and minorities, since they constitute the least active segment of the US population. The purpose of the present investigation was to compare motivations and barriers to exercise in African American and European American women 60 years and older.

\section{Methods}

\section{Participants}

A sample of 204 older female volunteers (89 European American and 115 African American) ranging in age from 60 to 86 years $(72+9)$ completed a pencil-and-paper questionnaire developed by Schuler et al (2004). Participants were actively recruited from local community centers, churches, and independent living facilities in the southeastern United States. Once permission was obtained from supervising personnel at the sample sites, researchers visited each site and verbally recruited participants.

\section{Procedure}

A brief overview of the procedures and purpose of the study was provided to all respondents at the beginning of the study. Respondents were then asked to sign an informed consent and complete the study survey. At each site, the researchers were present during the completion of the survey questionnaire to ensure accuracy and completeness of survey responses; participants were encouraged to ask questions when needed. The questionnaire took approximately 20 minutes to complete and was composed of two parts: general information (age, sex, height, weight, race, level of income, and education) and a list of barriers and motivations to choose from. Level of income was assessed by asking individuals to indicate if their annual household income was below $\$ 20,000(=1)$, between $\$ 20,000$ and $40,000(=2)$, or greater than $\$ 40,000(=3)$. Level of education was determined by asking individuals to choose one of the following categories: $1=$ grade school or left high school before graduation, $2=$ high school graduate, junior college, or technical/ trade school, and $3=$ college graduate (bachelors, masters, or doctorate).

\section{Assessment of Barriers and Motivations to Exercise}

The methodologies employed when studying perceived barriers and motivations to exercise include open-ended questions (Connell, Davies, Rosenberg, \& Fisher, 1988), focus groups (Rohm Young, Gittelsohn, Charleston, FelixAaron, \& Appel, 2001), checking of the most to least important on a prepared list (Booth, Bauman, Owen, \& Gore 1997), or rating agreements with statements (O'Neill \& Reid, 1991). In the present study participants were asked whether they exercised regularly (Yes/No); they were then asked to check "all that applied" from a list of 10 motivations (if they answered yes) or a list of 6 barriers (if they answered no). The list was developed by Schuler et al. (2004) in a previous study examining body-shape perceptions and motivations to exercise in a large sample of older adults. In their study (Schuler et al., 2004), based on responses to open ended questions, categories were developed that best described all motivators and barriers reported by the participants. The resulting list of barriers and motivations (see Table 2) is comparable to other studies (Cohen-Mansfield, Marx, \& Guralnik, 2003; Schutzer \& Graves, 2004), including cross-cultural studies on older adults barriers 
and motivations to exercise (Dergance et al., 2003; King et al., 2000). For both, barriers and motivations, an "other" category was included to give participants an opportunity to expand should there be reasons not included in the list; no additional barriers and motivations were listed by participants.

\section{Statistical Analysis}

A one-way analysis of variance (ANOVA) was used to test for ethnic differences in anthropometric and demographic variables with ethnicity as the between subjects factor and age, height, weight, body mass index $\left(\mathrm{BMI}=\mathrm{kg} / \mathrm{m}^{2}\right)$, and level of education and income as dependent variables. Frequencies were calculated for all categorical variables; differences in categorical variables were assessed using chi-square. Means and standard deviations were calculated for all continuous variables; ANOVA's were used to test for differences in continuous variables. The grouping variables used for comparisons included ethnicity (African American/European American), and level of income (1-3). Significance was set at $\mathrm{p}<0.05$ for all tests.

\section{Results}

Participants' age, anthropometric, and demographic variables are summarized in Table
1. A significantly greater percentage of African American women (48\%) were obese compared to $13 \%$ of European American women $(\chi 2=$ $126.3, \mathrm{p}<0.01)$. The one-way ANOVA revealed significant ethnic differences in the level of education and income, body weight, and body mass index (BMI). African American women were significantly heavier $(F(1,203)=$ $27.72, \mathrm{p}<0.01)$, had significantly higher BMI's $(\mathrm{F}(1,203)=23.15, \mathrm{p}<0.01)$, and had significantly lower levels of education (F (1, $203)=17.72, \mathrm{p}<0.01)$ and income $(\mathrm{F}(1,203)=$ 14.97, $\mathrm{p}<0.01)$. The mean level of education reported for European American women was 2.2 (high school graduate/junior college; $\mathrm{SD}=$ 0.54), whereas the mean for the African American women was 1.84 (grade school/left high school before graduation; SD $=0.64$ ). The mean annual income reported for European American women was $2.0(\$ 20,000-40,000$; $\mathrm{SD}=0.48)$ and for African American women it was $1.60(<\$ 20,000 ; \mathrm{SD}=0.49)$. The majority of participants reported to exercise regularly (n $=125$ ); no ethnic differences were found in the reported frequency of exercise. Sixty-four percent $(\mathrm{n}=57)$ of European Americans reported to exercise regularly compared to $59 \%$ $(n=68)$ of African Americans.

Table 1

Age, Anthropometric, and Demographic Measures for African American (AA; $n=115)$ and European American Women (EA; $\mathrm{n}=89)$

\begin{tabular}{|l|c|c|c|c|}
\hline & MEAN (EA) & SD (EA & MEAN (AA) & SD (AA) \\
\hline Age (years) & 73.11 & 7.94 & 71.41 & 7.92 \\
\hline Weight (kg) & 67.90 & 14.99 & 80.29 & $14.58^{*}$ \\
\hline Height (meters) & 1.62 & 0.06 & 1.64 & 0.08 \\
\hline BMI $\left(\mathrm{kg} / \mathrm{m}^{2}\right)$ & 25.61 & 5.46 & 29.77 & $5.27^{*}$ \\
\hline Level of Income $^{\mathrm{a}}$ & 2.00 & 0.80 & 1.60 & $0.64^{*}$ \\
\hline Level of Education $^{\mathrm{b}}$ & 2.20 & 0.54 & 1.84 & $0.64^{*}$ \\
\hline
\end{tabular}

${ }^{\mathrm{a}}$ Level of Income: $1=<\$ 20,000,2=\$ 20,000-40,000$, and $3=>\$ 40,000$.

${ }^{\mathrm{b}}$ Level of Education: 1 = grade school or left high school before graduation, 2 = high school graduate, junior college, or technical/trade school, and $3=$ college graduate.

$*=$ significant at $\mathrm{p}<0.01$. 


\section{Barriers and Motivations to Exercise} Chronic health or physical problems were the most frequently cited barriers to exercise for older African American as well as European American women (17.5\%); the most frequently cited motivation to exercise $(48.7 \%)$ for both ethnic groups was to improve/maintain their health (see Table 2). Significant ethnic differences were found for one barrier ("too expensive") and one motivation ("doctor's orders). Significantly more European American women perceived expenses to be a barrier to exercise $\left(\chi^{2}=3.94, \mathrm{p}<0.05\right)$ and significantly more African American women $\left(\chi^{2}=9.79, \mathrm{p}<\right.$ $0.01)$ reported to exercise because their doctor told them to compared to the European American women. When level of income was used as a grouping variable, no differences were found in the perceived barriers. With respect to motivations, a significant difference was found for "improve/maintain health" $\left(\chi^{2}=7.45\right.$, $\mathrm{p}<0.05)$; women in the highest income category (annual income $>\$ 40,000$ ) cited improved health as a motivation to exercise with the greatest frequency (68.4\%). Even though it did not reach statistical significance $\left(\chi^{2}=5.61, \mathrm{p}=0.06\right)$ a trend was apparent suggesting an inverse relationship between level of income and "doctor's orders" as a motivation to exercise. Women in the highest income bracket reported "doctor's orders" least frequently as a motivation to exercise ( $10.5 \%$ versus $30.1 \%$ ). Furthermore, the results of a univariate ANOVA, with BMI as the dependent variable and level of income as the fixed factor, revealed that women in the lowest income bracket had a significantly higher BMI $\left(29.7 \mathrm{~kg} / \mathrm{m}^{2}\right)$ compared to those in highest income bracket $\left(26.3 \mathrm{~kg} / \mathrm{m}^{2}\right)$ $(\mathrm{F}(2,188)=4.93 ; \mathrm{p}<0.01)$.

Table 2

Barriers and Motivations to Exercise by Ethnicity (African American, European American)

\begin{tabular}{|l|c|c|}
\hline Barriers And Motivations To Exercise & African American (\%) & European American (\%) \\
\hline Barriers & & \\
\hline Chronic Health Problems & 14.8 & 20.2 \\
\hline Causes Too Much Pain & 13.9 & 13.5 \\
\hline Already Active Enough & 13.9 & 12.4 \\
\hline No Self-Discipline & 11.3 & 13.5 \\
\hline Nobody to Exercise With & 12.2 & 11.2 \\
\hline Don't Know How & 12.2 & 10.1 \\
\hline Don't Have Time & 12.2 & 10.1 \\
\hline Exercise Is for Young People & 7.0 & 7.9 \\
\hline Limited Access/Transportation & 7.0 & 7.9 \\
\hline Too Expensive & 0.9 & $5.6^{*}$ \\
\hline Motivations & & 49.4 \\
\hline Improve Health & 48.7 & 40.4 \\
\hline Makes Me Feel Better & 49.1 & 43.8 \\
\hline Improve Physical Abilities & 45.2 & 38.2 \\
\hline Will Help Me Live Longer & 34.8 & 27.0 \\
\hline Something To Do With Friends & 31.3 & $14.6^{*}$ \\
\hline Doctor's Orders & 33.9 & \\
\hline
\end{tabular}




\section{Discussion}

This study examined barriers and motivations to exercise in largely understudied population, namely, older African American and European American women. The most important finding of this study was that African American women reported to exercise because "their doctor told them to" with significantly greater frequency compared to European American women. Furthermore, a trend was apparent suggesting an inverse relationship between level of income and "doctor's advice" as a motivation to exercise. The women with the highest annual income were the least likely to exercise on their "doctor's orders". Even though there was a statistically significant difference between European American and African American women with respect to "expenses" as a barrier to exercise (5.6\% versus $0.9 \%$ respectively), practically the difference seemed less important; only one African American and five European American women perceived exercise as too expensive. Similar to other studies in older adults, the top barrier to exercise for the older women in this study were chronic health problems, pain, and the perception that they were already active enough; the top motivations cited included improved health, feeling better, and improved physical abilities.

It is generally agreed upon that physician's play a key role in changing older adults' behavior to include regular physical activity. In 1995, the Centers for Disease Control (CDC) and the American Collage of Sports Medicine (ACSM) recommended that physicians routinely counsel patients to adopt and maintain regular physical activity. It was suggested that because patients respect their physician's advice they are more likely to adopt regular physical activity when counseled by their physician to do so (Pate et al., 1995). In general, Americans average 3.1 office visits to their doctor per year (Cherry, Burt, \& Woodwell, 2003). In light of the inherent challenges the aging process poses, such as increased vulnerability to disease and disability, it seems reasonable to assume this number to be even higher in older adults. Undoubtedly, the respect for their physician's advice and the frequency with which older adults visit their physician, underscores the importance of physician counseling about exercise in this population.

However, despite the pivotal role physicians play in promoting regular physical activity, national rates of physician counseling about exercise is low. In a recent study that assessed the results of the 1997 BRFSS in seven states and Puerto Rico (Bender et al., 1997) found that $42.3 \%$ of the general adult population reported receiving physician's advice to exercise with rates ranging from $32.6 \%$ (Iowa) to $70.4 \%$ (Puerto Rico). Prevalence rates also varied depending on age, gender, education, ethnicity, and presence of disease. Women (44.3\%), older adults (52\%), persons with less education (44.2\%), Hispanics (60.7\%), and individuals who reported a history of cardiovascular disease $(70.3 \%)$, were more likely to receive advice from their physician to exercise. Those least likely to receive advice included young adults $(31.2 \%)$ and non-Hispanic whites $(38.7 \%)$. The authors speculated that some physicians may not counsel their patients because they lacked training or did not believe their counseling would be effective. Furthermore, they hypothesized that some physicians may base counseling on the presence of risk factors rather than actual exercise behavior. A failure to counsel disease free healthy older adults about exercise represents an important missed opportunity for primary disease prevention.

Based on their findings (Bender et al., 1997) it is tempting to speculate that differences in body weight rather than ethnicity might explain the significant difference observed in our study between African American women and European American women with respect to the prevalence of physician counseling about exercise. Only $14.6 \%$ of European American women reported to exercise because their doctor told them to do so, compared to $33.9 \%$ of the African American women. The African American women in our study were significantly heavier compared to the European American women; being overweight is a risk factor for a variety of diseases such as cardiovascular disease, diabetes, or hypertension. Hence, 
physicians' counsel to exercise may have been limited to treating a problem (i.e. overweight) rather than to preventing it. Similar findings were reported by Blade et al. (2003), Damush, Stewart, Mill, King, \& Ritter (1999), Wee, McCarthy, Davis, \& Phillips (1999), who investigated the prevalence and correlates of physician counseling about exercise in older adults. In all three studies, the presence of risk factors and having a high body mass index was positively associated with increased reports of having received physicians' advice about exercise. A practice by physicians to limit counseling to exercise to the presence of risk factors may also help to explain the apparent trend toward an inverse relationship between level of income and "doctor's orders" as a motivation to exercise. The women in the highest income bracket reported "doctor's orders" least frequently as a motivation to exercise; the women in the highest income bracket also had the lowest BMI's.

\section{Conclusions}

This study investigated differences in motivations and barriers to exercise in African American and European American women 60 years and older. Similar to other studies in older adults, the top barriers to exercise for the older women in this study were chronic health problems, pain, and the perception that they were already active enough; the top motivations cited included improved health, feeling better, and improved physical abilities. In light of the pivotal role physicians play in promoting regular physical activity in older adults, it is important to emphasize that both ethnic groups selected "doctor's orders" least frequently as a motivation to exercise. Furthermore, African American women reported to exercise because "their doctor told them to" with significantly greater frequency compared to European American women. We hypothesized that differences in body weight rather than ethnicity might explain this finding. In order words, physicians might view exercise as a way to treat a problem rather than to prevent it.

It is important to note that the survey was subject to some limitations. The data were selfreported by older adults and therefore subject to recall bias. The methodology employed by this study (checklist presented to participants) might have introduced bias. The study sample was drawn from community centers and independent living facilities from the southeastern part of the United States so the results do only apply to this or similar populations.

\section{References}

Bender, B., Wineski, A., Jiles, R., Hann, N., Mann, L., Redman, L. et al. (1999, February). Physician advice and individual behaviors about cardiovascular disease risk reduction. Seven states and Puerto Rico, 1997. Morbidity and Mortality Weekly Report, 48(1), 74-77.

Blade, A., Figueras, J., Hawking, D. A., \& Miller, J. R. (2003). Physician advice to the elderly about physical activity. Journal of Aging and Physical Activity, 11, 90-97.

Booth, M. L., Bauman, A., Owen, N., \& Gore, C. J. (1997). Physical activity preferences, preferred sources of assistance, and perceived barriers to increased physical activity among physically inactive Australians. Preventive Medicine, 1, 131-137.

Cherry, D., Burt, C., \& Woodwell, D. (2003). National ambulatory medical care survey: 1991 summary. Hyattsville, MD: National Center for Health Statistics. Vital Health Statistics, 337.

Cohen-Mansfield, J., Marx, M. S., \& Guralnik, J. M. (2003). Motivations and barriers to exercise in an older community-dwelling population. Journal of Aging and Physical Activity, 11, 242-253.

Connell, C. M. , Davies, R. M., Rosenberg, A. M., \& Fisher, E. B. Jr. (1988). Retiree's perceived incentives and barriers to participation in health promotion activities. Health Education ResearchTheory and Practice, 3, 325-330.

Damush, T. M., Stewart, A. L., Mills, K. M., King, A. C., \& Ritter, P. L. (1999). Prevalence and correlates of physician recommendation to exercise among older adults. Journal of Gerontology: Medical Sciences, 54A, M423-427. 
Dergance, J. M., Calmbach, W. L., Dhanda, R., Miles T. P., Hazuda, H. P., \& Mouton, M. P. (2003). Barriers to and benefits of leisure time physical activity in the elderly: differences across cultures. Journal of the American Geriatrics Society, 51, 863-868.

Ebrahim, S., \& Rowland, L. (1996). Towards a new strategy for health promotion for older women: determinants of physical activity. Psychology, Health, Medicine, 1, 29-40.

Jones, D., Ainsworth, B., \& Croft, J. (1998). Moderate leisure-time physical activity: Who is meeting the public health recommendations? A national cross-sectional study. Archives of Family Medicine, 7, 285-289.

King, A. C., Castro, C., Wilcox, S., Eyler, A. A., Sallis, J. F., \& Brownson, R. C. (2000). Personal and environmental factors associated with physical inactivity among different racial-ethnic groups of U.S. middle-aged and older-aged women. Health Psychology, 19, 354-364.

Mâsse, L. C., \& Anderson, C. B. (2003). Ethnic differences among correlates of physical activity in women. American Journal of Health Promotion, 17, 357-360.

O'Neill, K., \& Reid, G. (1991). Perceived barriers to physical activity by older adults. Canadian Journal of Public Health, 82, 392-396.

Pate, R. R., Pratt, M., Blair, S. N., \& Haskell, W. L., Macera, C. A., Bouchard, C., et al. (1995). Physical activity and public health. A recommendation from the Centers of Disease Control and Prevention and the American College of Sports Medicine. Journal of the American Medical Association, 273, 402-407.

Rohm Young, D. J., Gittelsohn, J., Charleston, J., Felix-Aaron, K., \& Appel, L. J. (2001). Motivations for exercise and weight loss among African-American women: focus group results and their contribution towards program development. Ethnicity \& Health, 6, 227-245.

Schuler, P. B., Broxon-Hutcherson, A., Philipp, S. F., Ryan, S., Isosaari, R. M., \& Robinson, D. (2004). Body-shape perceptions in older adults and motivations for exercise. Perceptual and Motor Skills, 98, 1251-1260.

Schutzer, K. A., \& Graves, B. S. (2004). Barriers and motivations to exercise in older adults. Preventive Medicine, 39, 1056-1061.

US Department of Health and Human Services. (1996). Physical activity and health: A report of the Surgeon General. Atlanta, GA: US Department of Health and Human Services, Center for Disease Control Prevention.

Wee, C. C., McCarthy, E. P., Davis, R. B., \& Phillips R. S. (1999). Physician counseling about exercising. Journal of the American Medical Association, 282, 1583-1588.

\author{
Author Information \\ Petra B. Schuler \\ University of West Florida \\ Department of Health Leisure and Exercise Science \\ 11,000 University Parkway \\ Pensacola, FL 23514 \\ Ph.: 850-474-2596 \\ Fax.: 850-474-2106 \\ E-Mail: pschuler@uwf.edu \\ Jane L.P. Roy \\ Debra Vinci \\ Steven F. Philipp \\ Samantha J. Cohen \\ University of West Florida \\ * corresponding author
}

